\title{
A AUTORIA EM QUESTÃO A PARTIR DE FOUCAULT: AUTOR, DISCURSO, SUJEITO E PODER
}

Marco Antônio Sousa Alves

(UFMG)

\section{RESUMO}

O que é um autor? Essa questão foi posta em 1969 por Michel Foucault e permanece ainda hoje sem uma clara resposta. Com as novas transformações no exercício da função-autor promovidas, sobretudo, pela internet e pelos meios digitais, a questão do estatuto da autoria parece ganhar ainda mais destaque. Afinal, o que restará da figura moderna do autor? Procurando contribuir para novas investigações nesse domínio, proponho neste artigo retomar as reflexões de Foucault no sentido de fixar algumas importantes balizas e de oferecer um quadro mais amplo e aprofundado da questão da autoria, articulando-a com três grandes temas da tradição filosófica: o discurso, o sujeito e o poder.

PALAVRAS-CHAVE: Autoria; Discurso; Sujeito; Poder.

\section{Introdução}

Em 22 de fevereiro de 1969, Michel Foucault proferiu uma famosa conferência, intitulada "O que é um autor?", em um encontro da Sociedade Francesa de Filosofia. Esse texto, que foi novamente apresentado no ano seguinte nos Estados Unidos, recebendo uma versão em inglês ligeiramente modificada, teve um importante impacto nas discussões acerca do estatuto da autoria, especialmente no seio dos estudos literários. Além dessa apresentação, outros dois importantes trabalhos de Foucault desenvolvidos na mesma época, na virada da década de 1960 para os anos 1970, também abordaram diretamente a questão da autoria. São eles: A arqueologia do saber, publicado em março de 1969, e $A$ ordem do discurso, sua aula inaugural no Collège de France, proferida em 2 de dezembro de 1970. 
Segundo Foucault, tomando por base os três textos mencionados acima, não basta escrever ou produzir algo para que sejamos, imediatamente, erigidos à condição de autor. É no seio de determinada ordem do discurso que essa posição-sujeito aparece e entra em funcionamento. Sendo assim, é preciso investigar as circunstâncias historicamente constituídas que permitem aos indivíduos que escrevem possuírem certa personalidade autoral. A autoria, na literatura, nas ciências, nas artes ou na filosofia, é resultado de uma construção, marcada por continuidades, deslizamentos e rupturas, que fizeram de nós aquilo que ainda somos hoje em grande medida: autores, responsáveis por nossa "obra", portadores de certos privilégios hermenêuticos e detentores de direitos patrimoniais e morais sobre ela.

Na conferência de 1969, Foucault não se satisfez em simplesmente repetir a "afirmação oca" da morte do autor, procurando, mais do que isso, analisar esse espaço deixado vazio e as funções nele exercidas (FOUCAULT, 2001b, p. 821). Não podemos mais ficar satisfeitos com a mera negação da evidência e da universalidade da noção de autor, mediante a sustentação de seu caráter complexo e variável. É preciso compreender melhor essa complexidade e variação. Afinal, o que está envolvido na noção de autor? E como ela se modificou?

Não é tarefa fácil enfrentar as questões acima e nem se pretende aqui oferecer propriamente uma resposta a elas. Além da complexa natureza do autor, o mais desafiador reside na extrema transitividade dessa noção, a ponto de ser arriscado conferir à figura do autor uma existência que se estenda para além de certas experiências ocidentais posteriores ao século XVIII. De tão variável, qualquer traço pretensamente essencial conferido à autoria desfaz-se rapidamente mediante um rápido olhar na multiplicidade de suas experiências concretas. $\mathrm{O}$ autor ocupa um lugar no discurso e exerce determinadas funções, dentro de domínios específicos, de modo que, ao invés de perguntar pelo que é o autor, deveríamos voltar nossa atenção para a maneira como a autoria funciona.

Sendo assim, ao invés da pergunta pelo "ser do autor", é para o "funcionamento do autor" que gostaria de voltar a atenção. O autor será analisado aqui como um lugar que se pode ocupar no discurso e que exerce determinadas funções. Isso, como bem alertou Foucault, não significa negar a existência do "indivíduo que escreve", mas implica simplesmente em considerar que esse "indivíduo" não tem um lugar imediato e natural no discurso (FOUCAULT, 1971, p. 30-31). O indivíduo não toma diretamente a palavra, mas o faz sempre ocupando uma posição-sujeito específica. Nesse sentido, 
é preciso realizar uma análise da função no interior da qual algo como um autor pode vir a existir (FOUCAULT, 2001b, p. 846). Em suma, o indivíduo só funciona como sujeito do discurso e, em particular, como autor, ao ocupar um determinado lugar e assumir certas funções. Sem essa "investidura", não se pode falar propriamente em autor. Assim como, depois de investidos no e pelo discurso, também não se pode continuar a tratar os sujeitos como meros indivíduos naturais preexistentes.

As reflexões de Foucault, de certa forma, reconfiguraram nossa percepção sobre o tema e conduziram-nos a questionar a idéia moderna que recebemos, permitindo ainda vislumbrar novas perspectivas para a autoria através do entendimento de seu passado (JAZSI, 1994, p. 29; SAUNDERS; HUNTER, 1991, p. 483). Entendo que o autor, tomado como um construto moderno, está sofrendo uma profunda transformação. Estamos diante de uma radical reformulação da "ordem dos discursos", no seio da qual vemos emergir novas tecnologias de poder e posições-sujeito, que parecem apontar para o "anonimato do murmúrio" ou para formas inéditas de unificação e apropriação dos discursos, agora tomados como informações em uma grande rede compartilhada e mutante.

Creio que uma leitura mais abrangente e aprofundada das considerações feitas por Foucault tem ainda muito a oferecer, especialmente em um momento como o atual, no qual as posições anteriormente assumidas pelos indivíduos sofrem significativas transformações e novas experiências parecem colocar em xeque as formas tipicamente modernas de criação, circulação e recepção dos discursos. Mais do que o sonho de uma interpretação precisa e fiel da obra foucaultiana, o interesse principal que move a realização deste breve estudo é o desejo de refinar nossa compreensão acerca do complexo exercício da função-autor. Ou seja, mais do que comentar Foucault, o que se pretende é projetar, por meio de seus textos e fazendo uso de suas ferramentas conceituais, uma nova luz sobre a questão da autoria. Não sem razão, a análise que se segue terá uma forma menos exegética, repleta de citações e notas explicativas de detalhes hermenêuticos, e mais problematizadora, visando oferecer um quadro mais rico e articulado no qual a autoria possa ser pensada.

As considerações sobre a função-autor feitas por Foucault colocaram por terra nossas antigas e ingênuas "certezas" sobre a questão, mostrando que se trata de um problema complexo, que estabelece relações com o discurso, com o papel do sujeito e com os mecanismos de poder que permeiam o direito de deter e de se apropriar da palavra. Diante de tantos e tão grandes desafios, este artigo tem em vista realizar uma mera aproximação, uma tentativa 
de sintetizar alguns pontos da reflexão foucaultiana, aprofundando o estudo do funcionamento da autoria através da análise de três relações fundamentais: com o discurso (1), com o sujeito (2) e com o poder (3).

\section{Autor e Discurso}

Antes de analisarmos a relação estabelecida entre o autor e o discurso, convém começar perguntando: o que podemos entender exatamente por "discurso"? Ao invés de um logos ideal, constante e intemporal, abstratamente concebido, ele deve ser visto, a partir de Foucault, como um "acontecimento" (événement), uma realidade histórica contingente, uma série de enunciados efetivamente ditos, formulados e inscritos em uma materialidade específica. O projeto foucaultiano convida-nos a pesquisar diferentes formas históricas de práticas discursivas, analisando suas condições de existência e não mais suas condições universais de possibilidade.

Sem dúvida, o discurso é um dos temas que atravessam o pensamento de Foucault. Em A arqueologia do saber (1969), ele é concebido como um conjunto de enunciados marcados por um mesmo sistema de formação e definidos por um conjunto de condições de existência, possuindo sempre um suporte, um lugar e uma data específicos. Para além dessa definição em termos arqueológicos, a noção de discurso em Foucault sofre inúmeras redefinições e é alvo de diferentes propostas de análise ao longo de seu percurso intelectual. De início, Foucault emprega uma noção estruturalista e linguística herdada de Saussure, Lévi-Strauss e Benveniste. Em As palavras e as coisas (1966), encontramos uma visão do discurso associada a uma ordem das representações típica da idade clássica. Nos anos 1970, o discurso é tomado em um enfoque genealógico, mais voltado para as práticas discursivas (conjunto de técnicas, instituições, esquemas de comportamento, formas pedagógicas, etc.) e para as relações de poder (inseridas em dispositivos estratégicos). Por fim, nos últimos trabalhos de Foucault, desenvolvidos já na década de 1980, uma atenção especial é dada para a função do discurso como formador da subjetividade (CASTRO, 2009, p. 117-123; FRANK, 1989; REVEL, 2008, p. 39-40).

Não pretendo aprofundar aqui as variações que a noção de discurso sofre no pensamento de Foucault. Minhas considerações a seguir partem, de forma mais solta, da definição arqueológica mencionada mais acima. $\mathrm{O}$ discurso, de certa maneira, é destinado a viver em permanente tensão, entre algo em pura dispersão e algo unificado por determinados procedimentos. Ele transita entre dois pólos, um marcado pela desordem murmurante e outro 
pela ordem (que produz e também controla). Quanto mais próximo do murmúrio, mais o discurso é rico, profuso e perigoso. $\mathrm{O}$ reino da anarquia enunciativa, da fala irresponsável e sem controle: diz-se, fala-se... Estamos, nesse caso, na vizinhança do falatório, do rumor, da boataria e do ruído informe (LECLERC, 1998, p. 63). Por outro lado, quanto mais ordenado, mais raro e domesticado é o discurso. Estamos, nesse caso, nas cercanias da obra, da fala estatutária (do professor, do escritor, etc.) e do pronunciamento formal.

Em certo sentido, toda sociedade impõe uma ordem ao discurso e faz o mesmo transitar de um pólo ao outro, afastando-o do ruído incessante ou do murmúrio descontrolado. A imagem da palavra absolutamente livre, ao alcance de todos, que circula sem qualquer limitação, ao invés de um sonho, tende a ser vivenciada em uma sociedade como um pesadelo: a ameaça de cairmos em uma espécie de "selvageria discursiva". É comum encontrarmos, ao longo da história, a manifestação desse temor nos momentos em que a ordem do discurso é abalada e seus procedimentos de ordenação colocados em xeque, o que ocorre, por exemplo, quando uma nova técnica de inscrição e difusão discursiva aparece. Com o advento da internet e dos meios digitais não está sendo diferente. Temos medo da misteriosa riqueza e da possível violência inscrita na profusão desordenada da palavra. A sociedade, de certa forma, "civiliza a palavra", confere-lhe um lugar, um sentido.

Civilizar a palavra significa, sobretudo, conjurar e domesticar o perigo da selvageria discursiva, o que é feito mediante a determinação de quem pode falar, como pode fazê-lo, quando e de que forma, com qual valor, etc. Em suma, toda sociedade caracteriza-se por estabelecer uma ordem do discurso, que ela produz e, ao mesmo tempo, organiza e controla (FOUCAULT, 1971, p. 10-11). Nesse sentido, por exemplo, o papel da Universidade, já faz alguns séculos, consiste em exercer uma espécie de monopólio de seleção e de formatação dos saberes, desqualificando e eliminando o "saber em estado selvagem" (FOUCAULT, 1997, p. 163).

Mais ainda, toda sociedade pode ser definida pela modalidade de existência dos discursos que põe em funcionamento. Ou seja, podemos estudar uma sociedade a partir das formações discursivas que ela engendra, analisando, por exemplo, quais são as posições-sujeito disponíveis e como o poder da palavra é articulado a outros jogos de poder. O estudo da autoria pode ser inserido nesse contexto, como sugere Foucault, como uma introdução a uma tipologia dos discursos, ou seja, a análise da função-autor poderia servir de critério de distinção das grandes categorias de discursos, e também como uma introdução a uma análise histórica dos discursos, a partir do estudo dos 
modos de circulação, valorização, atribuição e apropriação dos discursos, que variam de cultura para cultura (FOUCAULT, 2001b, p. 838).

O discurso ganha, com a figura do autor, uma suposta unidade, coerência e inteligibilidade. $\mathrm{O}$ autor funciona como um "princípio de rarefação do discurso", ou seja, ele rarefaz a proliferação anônima da palavra impondo-lhe um lugar, ordenando-a, atribuindo-a a alguém e garantindo-lhe uma singularidade e uma visibilidade social. Além de produzir discursos, o autor, visto como um procedimento interno de controle e organização do discurso, é também uma espécie de "policial da ordem", alguém que domestica a palavra.

Seguindo a proposta da aula inaugural de Foucault no Collège de France, todo esse processo de produção, organização e controle do discurso faz-se através de certos procedimentos (como o exercício da função-autor) e toma corpo junto a um vasto conjunto de técnicas, instituições e comportamentos. Caminhando em uma direção genealógica, Foucault acena para uma nova análise do discurso em termos de dispositivos e práticas. Sendo assim, mais do que uma questão puramente discursiva (ou de procedimentos internos ao discurso), é importante analisar como esses procedimentos, entre eles a função-autor, envolvem práticas sociais e relações de poder específicas.

Nem toda sociedade produz e controla o discurso através do exercício da função-autor, e mesmo quando o faz, isso não significa que haja um funcionamento universal e uniforme dela. Mesmo nas culturas e nos domínios nos quais a função-autor está presente, como na literatura, na ciência e na filosofia ocidentais a partir do século XVIII, ainda assim sua função não se realiza sempre da mesma maneira.

Para finalizar essas considerações acerca da relação entre autor e discurso, é importante deixar alguns pontos mais claros. Primeiro, é preciso ter em mente que o autor é tomado aqui como uma posição ocupada por um indivíduo em uma prática discursiva, ou seja, como o sujeito de um enunciado, aquele que toma a palavra, que escreve ou que produz um discurso. Como se pode perceber, é uma definição bem ampla que vai muito além do espaço propriamente literário, científico ou artístico, embora esses sejam os domínios por excelência dos discursos autorais modernos. Essa ampliação da análise do autor explica, em parte, porque os estudos realizados no âmbito da crítica e da teoria literárias sobre a figura do autor (que são em grande número e em diversas perspectivas) constituem apenas uma pequena parte do problema mais geral do funcionamento do autor.

Outra observação que convém ser feita diz respeito ao enfoque adotado. O estudo da autoria que foi delineado por Foucault pretende articular 
práticas discursivas e não discursivas, de modo que o autor não pode ser reduzido a uma simples figura intradiscursiva, nem a uma mera personagem sócio-cultural. Ainda que seja importante compreender como o sujeito funciona no interior do discurso (quais são suas posições e funções), é preciso reconhecer que os discursos não são construtos puramente formais que "pairam" sobre as instituições e as culturas. Ou seja, o autor, embora esteja associado a uma função enunciativa e funcione intradiscursivamente, articula esses elementos com certas modalidades institucionais e sociais de aparição, circulação e seleção dos discursos (BUCH-JEPSEN, 2001, p. 52-3; HAYEZ, 2005, p. 190).

Por outro lado, o autor não deve ser descrito apenas como uma figura social. Logo no início da conferência sobre o que é um autor, Foucault explica que deixará de lado, em sua exposição, a análise histórico-sociológica da personagem do autor (FOUCAULT, 2001b, p. 820). Mais do que um abandono ou um desdém por esses estudos, a atitude de Foucault reflete uma opção por suspender temporariamente certas questões. Ao invés do estatuto social conferido ao autor em nossa cultura ou do sistema de valorização social no qual ele é inserido, a apresentação de Foucault privilegiou a análise da relação entre o autor e o texto, em uma reflexão que acentuará, justamente, a impossibilidade de reduzirmos o autor a uma instância meramente não discursiva (o indivíduo prévio, de "carne e osso").

Não resta dúvida que as práticas sociais são um aspecto fundamental em um estudo genealógico, mas isso não implica que devamos abraçar uma abordagem que se limita a descrever essas práticas. Mais do que pela posição social efetiva, é pela função que exerce em um modo de existência dos discursos que o autor é definido. Essa distinção nem sempre é bem percebida, o que conduz alguns comentadores a situarem a proposta de Foucault como uma mera história sócio-cultural da autoria (BENNETT, 2005, p. 22). Embora as práticas não discursivas tenham um papel importante em sua análise, e apesar de suas breves reflexões sobre a autoria terem dado origem a uma série de estudos nessa direção mais histórica e cultural, acredito que é inapropriado associar, sem mais, o projeto foucaultiano a esse tipo de empreitada.

Em resumo, não é possível reduzir o autor a um indivíduo preexistente ao discurso (seja como uma pessoa de "carne e osso", seja tomado em sua psyché), nem a uma simples figura intradiscursiva, nem tampouco a uma mera personagem social. A função-autor aponta para uma relação complexa, de ordem intradiscursiva e também não discursiva (LECLERC, 1998, p. 61). Em suma, a abordagem foucaultiana não se confunde com aquelas 
que encontramos normalmente no seio do formalismo linguístico, das análises estruturais ou ainda na sociologia e nos estudos culturais. O objetivo, as estratégias metodológicas e o escopo de suas reflexões são de outra ordem.

\section{Autor e Sujeito}

Mais do que o discurso, talvez seja o sujeito, ou a história dos diferentes "modos de subjetivação", o tema central do pensamento de Foucault, como ele mesmo chegou a afirmar nos últimos anos de sua vida, provavelmente possuído por certa "ilusão retrospectiva" (FOUCAULT, 2001f, p. 1042). Mesmo sem concordar plenamente com essa afirmação, é preciso reconhecer a importância da questão do sujeito em qualquer análise do discurso. De fato, todo enunciado, para ser realizado, implica um sujeito, entendido como aquele que o enuncia. Mas, por sujeito, não devemos entender sempre a mesma coisa, com a mesma natureza e desempenhando o mesmo papel. As práticas discursivas não devem ser vistas como uma "operação expressiva", que tem por base um sujeito ou cogito universal, entendido como algo a priori, que serve de fundamento e confere uma base sólida e fixa para se analisar o discurso. Ao contrário, as práticas discursivas são determinadas por um conjunto de regras anônimas e historicamente situadas. Ainda que se aceite que existe um indivíduo particular que formulou o enunciado inicialmente, disso não se segue que há uma consciência falante invariável ou um autor inconteste prévio ao discurso.

O discurso não deve ser pensado como a manifestação de um sujeito preexistente que pensa e diz. Ao invés disso, o discurso especifica um papel para seus sujeitos, ele funciona de certa maneira, e seus agentes exercem determinadas funções. A função-sujeito é variável, assim como os modos de existência dos discursos. Por isso, para descrever um enunciado, é preciso determinar qual é a posição que pode e deve ocupar um indivíduo para ser o sujeito. E, na medida em que o sujeito se constitui e se especifica discursivamente, pode-se dizer que o discurso é formador de subjetividades. Se há algo prévio, uma espécie de "indivíduo real", de "carne e osso", não devemos confundi-lo com o sujeito do discurso, que é sempre uma especificação desse indivíduo supostamente concreto e imediato (FOUCAULT, 1969, p. 121-126). Quando se consideram as formações discursivas como multiplicidades, elas escapam ao reino do sujeito, que deixa de ser tomado como algo primeiro ou prévio em relação ao discurso. Se há algo primeiro ou anterior ao discurso, trata-se não de um sujeito, mas sim de um "murmúrio anônimo", 
um ruído incessante e desordenado, a partir do qual surgem certos lugares para os sujeitos possíveis.

Em suma, o autor deve ser compreendido como um modo de existência do discurso, uma figura especificada e habilitada a formular certos enunciados. O autor não se confunde com o sujeito em geral, que não passa, aliás, de uma abstração. Ao invés de um sujeito constante e uma consciência fundadora, Foucault convida-nos a pensar em formas contingentes de subjetivação ou de se tornar sujeito. O autor, nesses termos, é apenas uma especificação da função-sujeito, uma posição que o indivíduo pode ocupar no discurso e, assim, tornar-se sujeito, tomar a palavra e desempenhar um papel determinado. Ser autor é uma forma de especificar o ser sujeito, de funcionar como sujeito do discurso. Assim, a função-autor não se confunde com outras posições que o indivíduo pode ocupar no discurso.

Por exemplo, o autor presente no discurso literário e científico moderno possui um estatuto e exerce funções bem distintas daquelas que encontramos no aedo grego arcaico, no monge copista medieval, ou no xamã guarani. Em certo sentido, há sempre um lugar para o indivíduo, uma função a ser exercida, mas que não é invariavelmente a mesma, embora tenhamos a tendência a naturalizar nossos lugares e funções, como se fossem evidentes e imutáveis. Todas as posições-sujeito acima indicadas, de certa maneira, são capazes de produzir enunciados. Mas aquilo que produzem não é propriamente uma "obra" e nem se pode dizer que se trata de uma "expressão" do sujeito. Não devemos buscar a essência da "criação" (ou da autoria) que uniria todas essas figuras tão díspares. Ao invés de meras manifestações de um mesmo sujeito universal invariável, é preciso levar a sério a contingência e a especificidade que caracterizam o sujeito e o discurso. Cada uma dessas posições-sujeito tem suas funções, seus suportes, suas formações históricas e seus lugares institucionais, assim como estão inseridas em jogos específicos de poder.

Além da contingência dos modos de ser do sujeito, que variam no tempo e de cultura para cultura, é importante observar que, no seio de uma mesma época e cultura, o indivíduo pode também ocupar vários lugares diferentes em um enunciado (como autor, narrador, signatário, relator, etc.), sem que nenhuma dessas figuras corresponda àquilo que se poderia chamar de um "eu primordial", mais fundamental e originário, do qual todos os enunciados derivariam. Mesmo dentro de uma mesma "obra", podemos encontrar diferentes posições-sujeito ou vários "eus", como no exemplo de Foucault do tratado de matemática, no qual o sujeito que fala no prefácio não é o mesmo que fala no percurso de uma demonstração ou o que fala das dificuldades e 
obstáculos encontrados no decorrer do trabalho (FOUCAULT, 1969, p. 123124; FOUCAULT, 2001b, p. 831).

Em suma, é como se tivéssemos uma corrente de especificações, do indivíduo particular somático para o sujeito, e deste para o autor. Esses processos, historicamente situados, não produzem figuras bem delimitadas e coerentes, imutáveis e universais. Longe disso, o sujeito e o autor são construções incertas quanto aos seus contornos, frágeis no que diz respeito à sua permanência, e instáveis em sua identidade, formada por migalhas que conformam a "ficção do eu". Foucault dedicou grande parte de suas investigações a mostrar como o sujeito e o autor são noções variáveis e complexas, funções incessantemente modificáveis. Ao invés de uma filosofia sistemática do sujeito ou uma decretação da morte do sujeito universal ou do autor criador originário, a empreitada de Foucault caracteriza-se, sobretudo, pelo interesse com relação às formas específicas de subjetivação, visando, dessa forma, problematizar e criticar nossas próprias posições-sujeito.

Por certo, encontramos também em Foucault considerações mais gerais e frases mais bombásticas e demolidoras do que meras problematizações de modos específicos de subjetivação. Por exemplo, as críticas ao sujeito fundador foram feitas, muitas vezes, nesse tom mais estrondoso, como uma morte, de Deus, do Homem ou do Autor. Nesse sentido, Angèle Kremer-Marietti tem razão de salientar que a crítica à noção de autor insere-se no interior de uma crítica mais geral à função fundadora atribuída à noção de sujeito, de modo que dizer que o autor morreu é como dizer que Deus ou o homem estão mortos (KREMER-MARIETTI, 1977, p. 98). Entretanto, entendo que esse aspecto (mais negativo e demolidor) foi excessivamente ressaltado na interpretação de Foucault. Assim, ficaram em segundo plano as propostas positivas de pesquisa e de reexame do sujeito e do autor, que também foram delineadas ou desenvolvidas em seus estudos. Como observa Foucault na conferência sobre o que é um autor, não basta repetir que o autor, o sujeito fundador, o homem ou Deus morreram, é preciso, além disso, realizar uma análise das funções que essa possível "morte" faz aparecer (FOUCAULT, 2001b, p. 821; MUCHAIL, 2002, p. 131-132).

Não se trata, de forma alguma, de negar por completo o sujeito-homem ou o sujeito-autor, mas de compreender o funcionamento deles. O problema é saber como (e sob quais condições) determinadas funções-sujeito puderam emergir e funcionar. Dessa forma, Foucault projeta novas experiências de pensamento e afasta-se da pergunta filosófica tradicional pela consciência 
fundadora, típica da modernidade, assim como da mera crítica pós-moderna (que simplesmente "mata" o sujeito fundador) (FOUCAULT, 2001c, p. 1033).

\section{Autor e Poder}

Para analisar a relação entre autor e poder, será preciso ir além das considerações feitas por Foucault acerca da autoria nos três textos mencionados no início deste artigo, quais sejam, “O que é um autor?" (1969), A arqueologia do saber (1969) e A ordem do discurso (1970). É ao longo dos anos 1970, sobretudo, que o tema do poder será explorado por Foucault, de modo que se recorrerá a outras fontes dessa época nas observações que se seguem.

Assim como o discurso e o sujeito, também o poder pode ser considerado um tema de destaque no pensamento de Foucault. Embora somente se tenha tornado central no chamado período genealógico, é importante observar que a questão nunca esteve completamente ausente. Em A arqueologia do saber, por exemplo, vemos Foucault reconhecer que o discurso é algo que, pela sua própria natureza, é objeto de uma luta política (FOUCAULT, 1969, p. 158). A importância do tema vai bem além de se assumir uma postura engajada e militante (que marcou Foucault, sobretudo, ao longo dos anos 1970), pois envolve uma problematização em termos estratégicos do funcionamento mesmo do discurso e das funções-sujeito.

Em vez de uma concepção global ou uma teoria geral do poder, o que interessa Foucault, em suas reflexões sobre o poder, são análises de conjuntos de práticas específicas permeadas por relações de força (FOUCAULT, 2001d, p. 402). Como afirma Edgardo Castro: "a pergunta de Foucault não é o que é o poder, mas como ele funciona” (CASTRO, 2009, p. 326). E em seu funcionamento, o poder é uma peça fundamental para a análise do discurso e o reexame do sujeito.

Os modos de ser do discurso envolvem complexas relações de poder. $\mathrm{O}$ poder não está fora do discurso, mas funciona através dele. O discurso, portanto, não deve ser visto como uma terra pura e refratária aos jogos mundanos, mas sim como o espaço mesmo no qual são travadas as mais diversas batalhas. Tomar a palavra, ser capaz de se apropriar dela, de lhe conferir determinado valor, são práticas que transmitem, reforçam e produzem relações de poder. Devemos, assim, examinar os diferentes papéis desempenhados pelo discurso no interior de um sistema estratégico, no qual o poder funciona (FOUCAULT, 2001e, p. 465).

Da mesma forma, o sujeito também não deve ser tomado como algo puro, originário, prévio às relações historicamente constituídas dos jogos de 
poder. As formas de subjetivação não são algo permanente, invariável ao longo da história, exterior às relações de poder. A função-autor, além de ser uma especificação da função-sujeito (um modo de subjetivação), envolve também uma "sujeição" ou "assujeitamento" (assujettissement), ou seja, uma espécie de ajuste do sujeito a uma ordem estabelecida. E mais do que "sujeitar" (assujettir), entendido como um procedimento de assimilação e domesticação, o poder instaura um processo no qual uma subjetividade se afirma positivamente, em um movimento propriamente constituinte de si. Assim, o poder é também produtor de individualidade. Em vez de simplesmente destruir, deformar ou debilitar o sujeito (que parece, nesses termos, algo puro, anterior e constante), o poder age de forma positiva, produzindo uma específica posição-sujeito.

O poder, sem dúvida, exclui e censura, mas também produz. Ao invés de puramente negativo, o poder é, sobretudo, produtivo e transformador: antes de reprimir, o poder produz o real (DELEUZE, 1986, p. 36; FOUCAULT, 1975, p. 227). Nesse sentido, na aula inaugural no Collège de France, Foucault, ao analisar o autor como um procedimento interno de controle e delimitação dos discursos, já procurou aliar o lado coercitivo e limitador do procedimento-autor (sua função restritiva e dominadora) com seu aspecto produtivo e positivo (seu papel multiplicador, que torna possível certa produção discursiva) (FOUCAULT, 1971, p. 38).

Ao retirar a centralidade do modelo jurídico negativo de conceber o poder, enfatizando, ao contrário, seu aspecto positivo e produtor, a análise genealógica problematiza também a relação entre o sujeito e o discurso. A ordem do discurso, que funciona através de certos procedimentos de controle e organização, não deve ser concebida como algo puramente repressor. Mais do que limitar a liberdade do indivíduo, a ordem estabelecida instaura lugares e posições para sujeitos possíveis. O discurso autoral, por exemplo, é uma produção, uma criação, um exercício de liberdade. Mas, claro, essa liberdade é limitada. Nem tudo é passível de ser dito, nem todos têm direito à palavra e aqueles que gozam desse privilégio são assimilados pela própria ordem que os investe desse poder.

O diálogo fictício entre Foucault e a instituição que inicia sua aula inaugural no Collège de France ilustra bem esse dilema. Enquanto Foucault revela sua ingênua expectativa de ver sua fala ressoar em um espaço aberto e transparente, no qual a verdade pudesse aparecer em sua forma pura, a instituição na qual acaba de ingressar lhe responde, ironicamente, que há muito 
cuida da aparição do discurso, colocando-o na "ordem das leis", cercando-o de solenidades e rituais de silêncio e atenção, de modo que o lugar que lhe foi conferido, uma cátedra no tradicional Collège de France, ao mesmo tempo que o honra, também o desarma (FOUCAULT, 1971, p. 8-9).

Há sim liberdade, porém ela reside não em um suposto poder ilimitado de transgressão, mas sim na luta contra a mera aceitação e domesticação, no desenvolvimento de uma atitude crítica de constante problematização de nossas próprias maneiras de pensar, falar e agir, de modo a provocar uma permanente transformação de si e das práticas discursivas. Essas transformações não devem ser pensadas como uma "revolução" ou uma "mudança geral", mas sim como uma espécie de "jogo com as regras", um combate que permite embaralhar a suposta evidência e necessidade da ordem estabelecida. Pensando nesse quadro genealógico, a crítica assume a forma de uma resistência sempre provisória, regional, que produz sem cessar novos procedimentos de normalização e de institucionalização. Assim, toda resistência ou liberação é, mais cedo ou mais tarde, integrada, assimilada e ordenada, de modo que toda ruptura tem um valor temporário e tende a sempre recomeçar, assumindo novas formas.

Essas breves considerações sobre as relações entre discurso, sujeito e poder já permitem perceber que estamos muito distantes de uma crítica do poder em termos de uma busca pela transgressão radical, de um contradiscurso subversivo ou de uma crítica ideológica do poder como mera inversão da realidade. Essas posturas chegaram a caracterizar alguns momentos do percurso foucaultiano, expressando-se claramente em sua análise da autoria. No início dos anos 1960, muito influenciado por Blanchot, Foucault associava o "desaparecimento do autor" à emergência de uma experiência de linguagem transgressora e subversiva, um "pensamento do lado de fora" (pensée du dehors) que contrapunha à ordem estabelecida um contradiscurso radical (FOUCAULT, 1966; FOUCAULT, 2001a). E, ao final da versão da conferência apresentada em 1970 nos Estados Unidos sobre o que é um autor, Foucault chegou a desenvolver uma reflexão sobre o estatuto ideológico do autor, descrevendo-o como uma construção característica da sociedade industrial e burguesa, marcada pelo individualismo e pela propriedade privada, que exerce o papel de "regulador da ficção". O mecanismo de poder associado ao exercício da função-autor (como entrave e manipulação) é enfatizado, sendo o autor reduzido a uma figura ideológica, uma mera inversão da realidade (FOUCAULT, 1984, p. 118-119).

Na chamada fase genealógica de Foucault, a partir dos anos 1970, essa postura é claramente abandonada. Foucault estabelece, como uma "precau- 
ção de método", a realização de uma análise ascendente do poder, que parta de "mecanismos infinitesimais" e não de "formas de dominação global". Ao invés de um discurso de poder e um contradiscurso de resistência ao poder, devemos tomar os discursos como "blocos táticos" no campo das relações de força (FOUCAULT, 1976, p. 131-134; FOUCAULT, 1997, p. 27). Nessa direção, ao analisar a emergência do autor moderno, convém mostrar como os elementos que conformaram o discurso sobre a autoria na modernidade estão associados a diferentes estratégias, que somente de forma muito simplificadora poderíamos reduzir a um único discurso dominante. Embora o funcionamento da função-autor possa servir aos interesses burgueses de domesticação e apropriação dos discursos, seria muito reducionista compreender o mecanismo autoral como uma mera estratégia consciente dessa classe.

Partindo das análises das relações de poder empreendidas por Foucault, podemos recolocar o problema da autoria e sua relação com o poder na modernidade. O saber sobre o autor (por exemplo, do direito autoral e da crítica literária) não devem ser tomados por meros efeitos ou simples traduções, ao nível do discurso teórico, provocados pelos meios materiais de produção editorial e pelo mercado livreiro. Ou seja, não devemos tomar o autor por uma mera construção ideológica, produto de um poder dominante (burguês), que tem sua emergência determinada por certos meios materiais de produção (como a impressão). Esses são, sem dúvida, elementos importantes na emergência do autor moderno, mas não constituem suas causas únicas ou privilegiadas. Essas relações, que não devem ser ignoradas, precisam, contudo, ser inseridas no seio de um quadro bem mais vasto, de um dispositivo que articula muitos outros elementos (CHARTIER, 1992).

As novas análises do poder trazem ainda uma importante conseqüência no que diz respeito ao problema da suposta "morte do autor". Ao invés de "matar" o autor para fazer nascer um contradiscurso radicalmente liberto das coerções da ordem estabelecida, ou de ver na figura do autor uma deturpação que inverte a "realidade" da criação discursiva, o mais conveniente seria, inspirando-se nas pesquisas levadas adiante por Foucault nos anos $1970 \mathrm{em}$ outros domínios (como vemos em Vigiar e punir e no primeiro volume da História da sexualidade), analisar como a emergência do autor moderno está ligada a uma mudança no regime de poder, com novos objetos, noções, sujeitos e funções.

O fato de não ser correto dizer simplesmente que o autor "morreu" não significa que seja impossível imaginar sociedades nas quais a função-autor não seja exercida. Esse exercício de reflexão heterotópica, contudo, não deve ser confundido com a esperança em uma sociedade plenamente 
livre, sem qualquer princípio coercitivo de organização discursiva. Mesmo sem a função-autor funcionar, a crença nessa suposta "terra da liberdade" é pura ilusão e fantasia. Ao invés disso, convém pesquisar o aparecimento, os deslizamentos e as transformações que marcam o funcionamento do discurso e as constituições do sujeito, e, quanto ao poder, é preciso analisar, juntamente com sua faceta produtiva, as formas emergentes de controle e dominação. Mais do que uma "transgressão" (transgression), trata-se de considerar as possibilidades sempre parciais e provisórias de "ultrapassagem" ou "liberação" (franchissement), que permitem novas experiências de pensamento e práticas éticas e políticas inovadoras (CASTELO BRANCO, 2008, p. 212).

A figura do autor (entendida como uma especificação da função-sujeito) e o discurso autoral (tomado como um modo de ser ou de existir do discurso) são, nesses termos, permeados por relações de poder, cujo funcionamento convém investigar mais de perto. Essas relações devem ser analisadas como jogos, em termos de táticas e estratégias, o que envolve também a consideração das lutas e resistências. As práticas autorais, em interação com outras práticas e instituições, criam dispositivos específicos de poder, que devem ser compreendidos como uma rede de relações que se estabelece entre elementos heterogêneos (discursos, instituições, regramentos, leis, enunciados científicos, medidas administrativas, proposições filosóficas, morais, etc.). É preciso, em suma, articular os fatos do discurso autoral (estético, literário, institucional, material, moral, etc.) aos mecanismos do poder (que vão bem além do direito autoral).

\section{Considerações finais}

Afinal, o que é um autor? Essa pergunta, colocada por Foucault em 1969, permanece ainda, em grande medida, sem uma resposta clara e definitiva. A autoria persiste sendo um problema, uma questão em aberto. As reflexões levadas a cabo por Foucault permitiram, sem dúvida, jogar alguma luz nesse tema, mas não muito mais do que isso. Apenas certas balizas foram estabelecidas, de modo que há ainda muito trabalho a ser feito, muitas investigações a serem realizadas. A proposta deste artigo pode ser compreendida nesse sentido, como uma tentativa de fixar com mais precisão alguns pontos de partida para essas novas pesquisas.

Acredito que as reflexões realizadas por Foucault sobre a autoria, embora sejam amplamente conhecidas, ainda não foram devidamente aprofundadas. As leituras realizadas, tanto nos estudos literários, quanto no âmbito filosófico, não exploraram, em sua maior parte, as relações que a questão da 
autoria estabelece com outros domínios importantes no pensamento foucaultiano. Talvez em razão desse déficit, a interpretação normalmente feita tende a ser muito parcial e excessivamente simplificadora, dando origem a aproximações apressadas e rotulagens indevidas. Toma-se facilmente Foucault, por exemplo, por um "pós-moderno", um "estruturalista" ou um "culturalista".

O esforço realizado aqui visa, sobretudo, fornecer uma articulação mais clara do problema da autoria com algumas tradicionais questões filosóficas exploradas por Foucault em diferentes trabalhos, quais sejam, as questões do discurso, do sujeito e do poder. A partir daí, certamente, resta muito trabalho a ser feito no sentido de compreendermos melhor o que é um autor e o que está acontecendo com essa figura nos dias de hoje.

Considero importante enfatizar a contemporaneidade da questão do estatuto da autoria. Entendo que a figura moderna do autor está sofrendo uma intensa e radical alteração. A internet e os novos meios digitais vêm desencadeando um processo que coloca em questão a forma-livro e a autoridade autoral, além de subverter as formas de controle e os modelos comerciais, muitos deles estabelecidos desde o século XVIII. Novas tecnologias de poder e inéditas posições-sujeito emergem no seio daquilo que se convencionou chamar de "cibercultura", entendida como uma formação histórica, um conjunto de práticas e representações que se baseiam nas redes telemáticas e que se desenvolvem com a crescente mediação da vida cotidiana pelas tecnologias da informação, que se tornam cada vez mais ubíquas.

O que resta ou restará do autor moderno? Somente seremos capazes de analisar criticamente as transformações atuais na ordem do discurso e no funcionamento da função-autor se levarmos em conta o processo histórico de constituição desses procedimentos, noções, sujeitos, práticas e conceitos tipicamente modernos que são ainda tão presentes. E mais do que uma crítica das transformações que marcam nosso tempo, acredito que esse esforço envolve, sobretudo, uma crítica de nós mesmos, de nosso modo de ser. 


\section{ABSTRACT}

What is an author? This question was raised in 1969 by Michel Foucault and still remains without a clear answer. The new transformations in the author-function operations, which are mainly promoted by the internet and the digital media, seem to put the question concerning the status of authorship even more in the spotlight. After all, what still remains from the modern figure of the author? In an attempt to contribute to new investigations on this domain, I propose here that we look back at Foucault's remarks in order to establish some important guidelines and sketch a broader and richer framework in which the question about authorship can be set. This framework articulates three capital topics in philosophical tradition: discourse, subject, and power. KEYWORDS: Authorship; Discourse, Subject; Power.

\section{REFERÊNCIAS}

BENNETT, Andrew. The author. London/New York: Routledge, 2005.

BUCH-JEPSEN, Niels. Le Nom propre et le propre auteur: qu'est-ce qu'une 'fonction-auteur'? In: JACQUES-LEFÈVRE, N.; REGARD, F. (dir.) Une histoire de la "fonction-auteur" est-elle possible?: actes du colloque organisé par le Centre de recherche LiDiSa (Littérature et Discours du Savoir), 11-13 mai 2000, E.N.S. Fontonay-Saint-Cloud. Saint-Étienne: Publications de l'Université de Saint-Étienne, 2001. p. 49-64.

CASTELO BRANCO, Guilherme. Atitude-limite e relações de poder: uma interpretação sobre o estatuto da liberdade em Michel Foucault. Verve, n. 13, p. 202-216, 2008. Disponível em: <http://revistas.pucsp.br/index.php/verve/article/view/5205>. Acesso em 13 dez. 2012.

CASTRO, Edgardo. Vocabulário de Foucault: um percurso pelos seus temas, conceitos e autores. Tradução de Ingrid Müller Xavier. Belo Horizonte: Autêntica, 2009.

CHARTIER, Roger. L'ordre des livres: lecteurs, auteurs, bibliothèques en Europe entre XIVe et XVIIIe siècle. Aix-en-Provence: ALINEA, 1992.

DELEUZE, Gilles. Foucault. Paris: Éd. de Minuit, 1986. 
FOUCAULT, Michel. Les mots et les choses: une archéologie des sciences humaines. Paris: Gallimard, 1966.

. L'archéologie du savoir. Paris: Gallimard, 1969.

. L'ordre du discours: leçon inaugurale au Collège de France prononcée le 2 décembre 1970. Paris: Gallimard, 1971.

. Surveiller et punir: naissance de la prison. Paris: Gallimard, 1975.

. Histoire de la sexualité I: la volonté de savoir. Paris: Gallimard, 1976.

. What is an author? In: RABINOW, P. (ed.). The Foucault Reader. London:

Penguin Books, 1984. p. 101-120.

. "Il faut défendre la société »: cours au Collège de France (1975-1976).

Édition établie sous la direction de François Ewald et Alessandro Fontana, par Mauro Bertani et Alessandro Fontana. Paris: Seuil/Gallimard, 1997.

. La pensée du dehors (1966). In: . Dits et Écrits I. 1954-1975. Paris:

Quarto Gallimard, 2001a. Texto n. 38, p. 546-567.

. Qu'est-ce qu'un auteur? (1969). In: . Dits et Écrits I. 1954-1975. Paris: Quarto Gallimard, 2001b. Texto n. 69, p. 817-849.

. Entretien avec Michel Foucault (1971). In: . Dits et Écrits I. 19541975. Paris: Quarto Gallimard, 2001c. Texto n. 85, p. 1025-1042.

. Pouvoir et savoir (1977). In: . Dits et Écrits II. 1976-1988. Paris: Quarto Gallimard, 2001d. Texto n. 216, p. 399-414.

. Dialogue sur le pouvoir (1978). In: . Dits et Écrits II. 1976-1988.

Paris: Quarto Gallimard, 2001e. Texto n. 221, p. 464-477.

. Le sujet et le pouvoir (1982). In: . Dits et Écrits II. 1976-1988. Paris:

Quarto Gallimard, 2001f. Texto n. 306, p. 1041-1062.

FRANK, Manfred. Sur le concept de discours chez Foucault. In: MICHEL FOUCAULT PHILOSOPHE. RENCONTRE INTERNATIONALE. Anales..., Paris 9, 10 , 11 janvier 1988. Paris: Éd. du Seuil, 1989. p. 125-136.

HAYEZ, Cécile. Le statut de l'auteur à partir de son rapport à l'écrit en droit et en littérature. In: HAYEZ, C.; LISSE, M. (éds.). Apparitions de l'auteur: études interdisciplinaires du concept d'auteur. Berne: Peter Lang, 2005. p. 167-190.

JASZI, Peter. On the author effect: contemporary copyright and collective creativity. In: JASZI, P.; WOODMANSEE, M. (eds.). The construction of authorship: textual appropriation in the law and literature. Durham/London: Duke University Press, 1994. p. 29-56.

KREMER-MARIETTI, Angèle. Introdução ao pensamento de Michel Foucault. Tra- 
dução de César Augusto Chaves Fernandes. Rio de Janeiro: Jorge Zahar, 1977. LECLERC, Gérard. Le sceau de l'œuvre. Paris: Éd. du Seuil, 1998.

MUCHAIL, Salma Tannus. Michel Foucault e o dilaceramento do autor. Margem, $\mathrm{n}$. 16, São Paulo, p. 129-135, 2002.

REVEL, Judith. Dictionnaire Foucault. Paris: Ellipses, 2008.

SAUNDERS, David; HUNTER, Ian. Lessons from the 'Literatory': how to historicise authorship. Critical Inquiry, vol. 17, n. 3, The University of Chicago Press, p. 479-509, spring 1991.

Recebido em: 31 de maio de 2015 Aceito em: 01 de setembro de 2015 